\title{
A brief history of therapy for traumatic spinal cord injury
}

\author{
Jason Lifshutz, M.D., AND Austin Colohan, M.D. \\ Department of Neurosurgery, Medical College of Wisconsin, Milwaukee, Wisconsin; \\ and Division of Neurosurgery, Loma Linda University Medical Center, Loma Linda, California
}

\begin{abstract}
There are few more devastating injuries that afflict man than those associated with spinal cord injury (SCI). The economic, psychological, and social impact are encompassing and enormous to the individual and society. During the last several years, there has been a renewed interest in the study of SCI, with the hope of finding a cure. It is appropriate, then, to examine the efforts accomplished throughout medical history. With this retrospective view, potential avenues for future treatment become more apparent and clear. As in the past, the integration of basic science and clinical innovation will create the path toward progress for treatment of this disease.
\end{abstract}

\section{KEY WORDS • spinal cord injury • history of medicine}

The frog instantly dies when the spinal cord is pierced; and previous to this it lived without head, without heart or any bowels or intestines or skin; and here therefore it would seem lies the foundation of movement and life. Leonardo da Vinci.

There are few more devastating injuries that afflict humans than those associated with SCI. From economic, psychological, and social perspectives, the impact of SCI is encompassing and enormous. ${ }^{1,6}$ Within the last several years, there has been a renewed interest in the study and treatment of these injuries, with the hope of finding a cure. Current research into SCI includes endeavors in both the basic science (molecular and genetic technologies), and clinical arenas (pharmacological and surgical interventions). This is clearly a very exciting time in the treatment of this devastating injury. Because of this renewed interest, it is both appropriate and timely to step back and examine the work and efforts that have preceded us in this field of study. With the lessons gleaned from the past, potential avenues toward future treatment may become more apparent and clear. As the famous surgeon Bilroth stated, "Only the man who is familiar with the art and science of the past is competent to aid in its progress in the future."14

\section{A BRIEF REVIEW OF SCI TREATMENT}

\section{Egyptian Period}

The affliction and suffering associated with fractures of the spinal column and injury to the spinal cord have attracted the interest of the medical community since the dawn of civilization. The first references to spinal column injury and SCI are found in the writings contained within

Abbreviations used in this paper: MR = magnetic resonance; $\mathrm{SCI}=$ spinal cord injury. the Edwin Smith Surgical Papyrus (Fig. 1). ${ }^{6,8,11,14}$ The document, dating to $2500 \mathrm{BC}$ and obtained by the Egyptologist Edwin Smith in 1862, ${ }^{8}$ is the first part of a textbook regarding bodily injuries, which are essentially described systematically from head to toe. ${ }^{8}$ The book comprises a series of 48 case histories that provide insight into Egyptian medicine of 2500 BC. Six case reports (Cases 29-33 and 48) refer to injuries of the spinal canal. ${ }^{6,8,11,14}$ The author describes, with great detail, the diagnosis and treatment of fractures, sprains, and open wounds involving the spinal column. Case 31 is thought to represent the first clinical report of SCI:

If thou examinest a man having a dislocation of his neck, shouldst thou find him unconscious of his two arms (and) his two legs on account of it while his phallus is erected on account of it, (and) urine drops from his member without his knowing it; his flesh has received wind: His two eyes are blood-shot; it is a dislocation of a vertebra of his neck extending to his backbone which causes him to be unconscious of his two arms....

Thou shouldst say concerning him ... an ailment not to be treated. ${ }^{8}$

Clearly the author of this treatise, who is believed (by some) to be the great physician and architect Imhotep (and an army surgeon by others), ${ }^{8}$ is a learned anatomist, physician, and surgeon. It is obvious from this narrative that the author possesses some knowledge of anatomy, physiology, neurology, and pathology, with the text's clinical description of paralysis, bladder incontinence, vasodilation, abdominal distention, and priapism. It is of great interest that no distinction is made, at this time, between spinal vertebral injury and the presence of the underlying spinal cord. This discovery is to come later. The prognosis for this injury, "an ailment not to be treated," remained the attitude of physicians for centuries.

The medical record, in relation to SCI, is poorly documented between the Egyptian period and the rise of Greek 


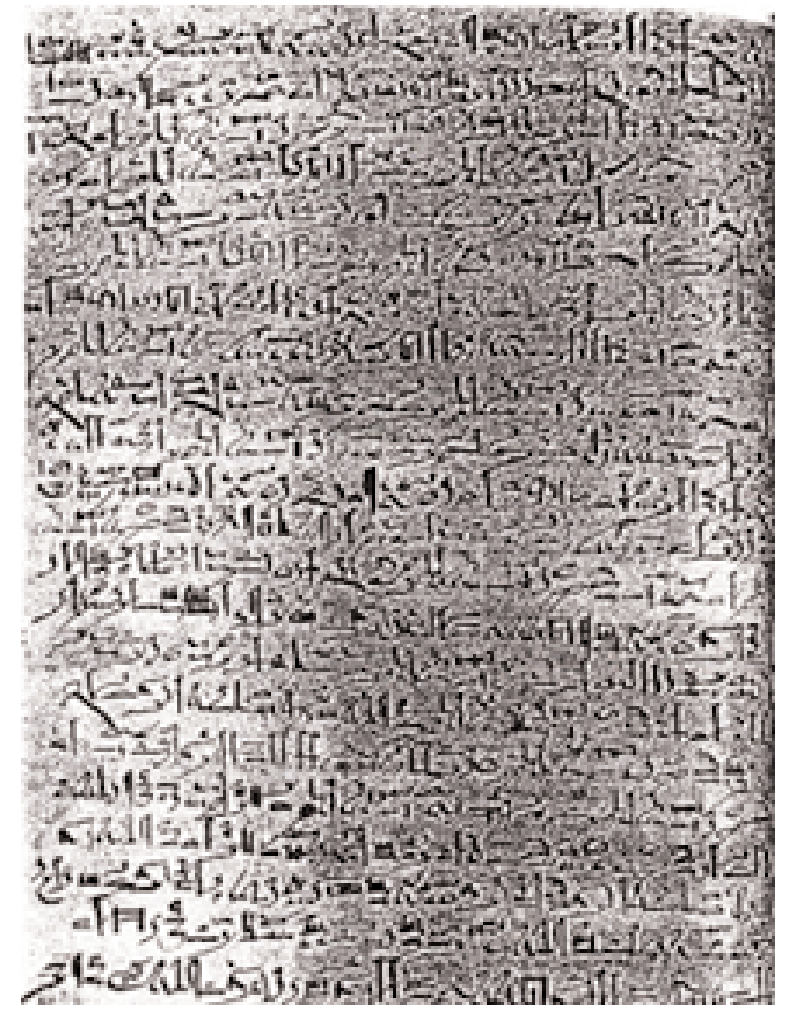

Fig. 1. Edwin Smith Surgical Papyrus Cases 29-31.

civilization. The lethal nature of spinal vertebral injury and SCI can next best be illustrated in Homer's Odyssey, where he presents the character of Elpenor, who became inebriated, climbed on a roof, and fell when startled by his friends. In falling from the roof, he broke his neck "and

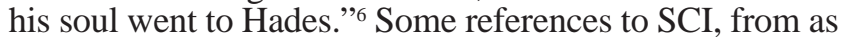
early as $1800 \mathrm{BC}$, can also be found in the Hindu civilization, with the concurrent utilization of axial traction. ${ }^{11}$ It appears, however, that the prognosis of these types of injuries did not change during this period. ${ }^{6}$

\section{Hippocratic and Galenic Period (500 BC-500 AD)}

Hippocrates (460-377 BC), considered both the father of medicine and orthopedics, discussed fractures/dislocations of the spinal vertebrae and their correlation to SCI (Fig. 2). ${ }^{11,12,14} \mathrm{He}$ is credited with some of the first clinical descriptions of chronic paralysis, with constipation, bladder difficulty, bed sores, and venous stasis of the lower extremities. He believed that poor outcomes associated with these patients were due to obstruction of the visceral organs, and he promoted special diets for the treatment of these clinical entities. 6,12 Additionally, Hippocrates is credited with developing methods for reducing spinal deformities by administering traction with the aid of his extension bench, the scamnun (Fig. 3). ${ }^{11,12,14}$ This device, with various modifications, has been used in the treatment of spinal disorders throughout history, up to the present day. He believed that there was no reasonable therapy for individuals with fractures combined with paralysis and that they were destined to die. ${ }^{11,12}$ Interestingly, he hypothesized that cure may be feasible if anterior reduction of the

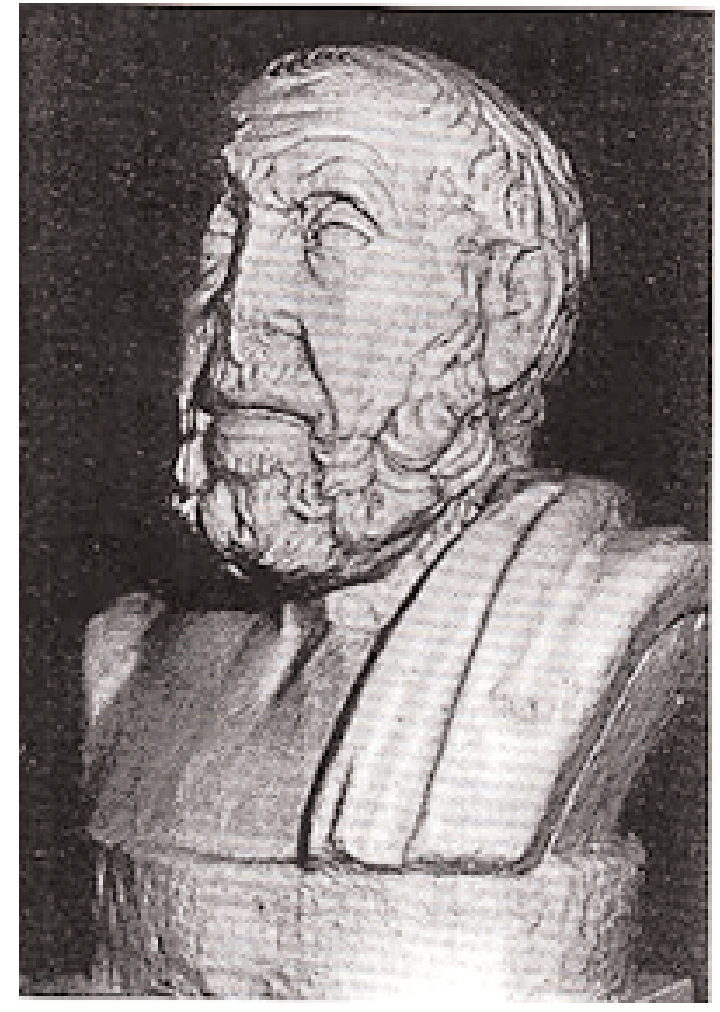

Fig. 2. Hippocrates (5th-4th Century BC).

fracture was possible, a precursor to anterior surgical decompression. ${ }^{11,12,14}$ What is not clear in the work of Hippocrates is the role and appreciation of the spinal cord. The basic science of this injury was still in its infancy.

The realization of the central role of the spinal cord in this process became apparent in the subsequent centuries. Aulus Cornelius Celsus $(30 \mathrm{BC})^{11,14}$ was the first to note rapid death following the injury to the cervical spinal

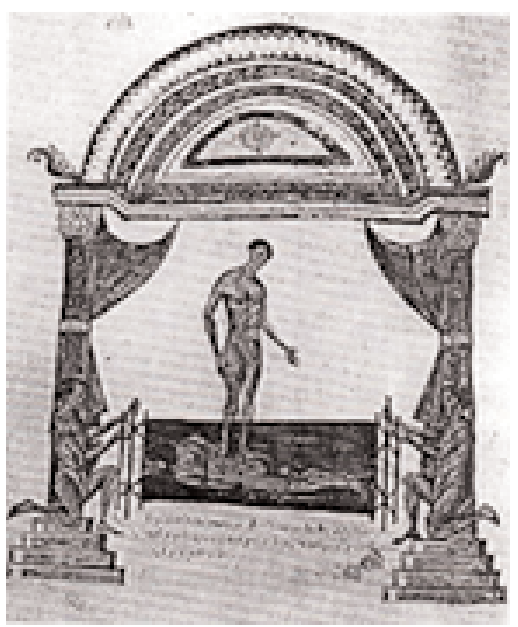

Fig. 3. The Hippocractic Board devised for the reduction of spinal curvatures. From the illustrated edition of Apollonius of Kitium commenting on the Hippocratic treatise "On Joints." Bibliotheca Medica Laurenziana, Florence (19th-10th Century AD). 
cord. ${ }^{11,14}$ This is thought to be the first reference to the spinal cord as the offending tissue in this disorder. ${ }^{14}$ In his writings, Celsus popularized the theories of Hippocrates, in reference to the use of his scamnun and spinal traction. ${ }^{11,14}$ Aretaeus (150 BC) ${ }^{11,14}$ was the first to define and differentiate the levels in SCI. In addition, he was the first to observe that some SCIs resulted in deficits on the ipsilateral side of the injury. ${ }^{14}$

The greatest advances in our understanding of the spinal cord dysfunction in this period were achieved through the work of Galen (150 BC) (Fig. 4). 6,11,13,14 Galen, who was considered to be the "second Hippocrates," 13 had the unique opportunity to study traumatic injuries to various regions of the body because of his travels to the clinics of Alexandria and his work with both gladiators and corpses. He is considered to be the father of experimental physiology, and perhaps his greatest work was illustrated in his studies of spinal cord function. In his works On Anatomical Procedures and On Affected Areas (Fig. 5) ${ }^{13}$ he proved experimentally (it was illegal to performed studies in animal vertebrae) that injury to the cord led to both paralysis and loss of sensation below the lesion. ${ }^{13}$ Additionally, his work demonstrated the differences in loss of function in relation to lesions at distinct levels of the spinal cord: ". . . it is obvious that the upper sections of the spinal marrow are more important than the lower."13 Furthermore, he is credited with the observations of functional differences between longitudinal and transverse lesions to the spinal cord. He found that longitudinal incisions had little apparent effect, whereas transverse incisions led to loss of function below the level of the lesion. Clinical-

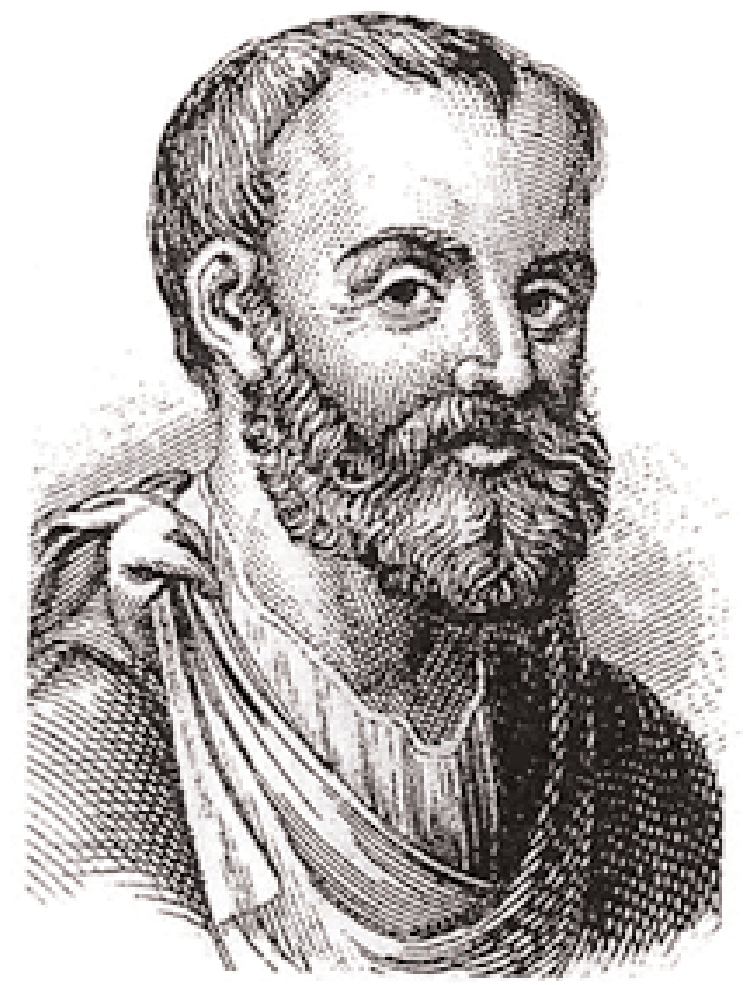

Fig. 4. Galen, the greatest physician since Hippocrates, in classical antiquity.

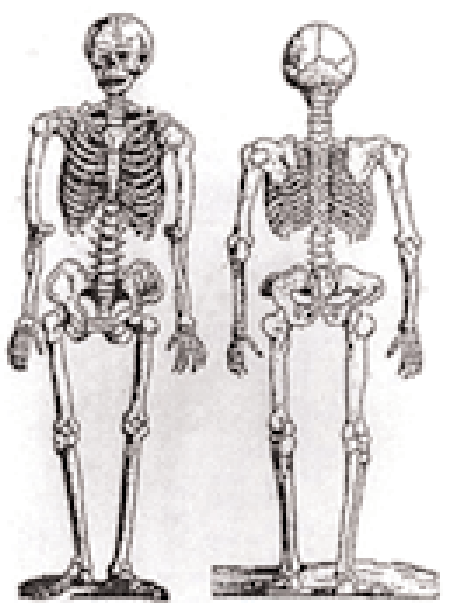

Fig. 5. Ventral and dorsal aspect of human skeleton. Woodcut illustrating the Greek text of J. Froben's edition of Galen's Works (Basel, 1538).

ly, Galen advocated the traction and reduction therapies described by Hippocrates and Celsus..$^{6,11,13,14}$ These same theories pertaining to manual reduction were later promoted by Oribasius (325-403)..$^{6,11,14}$ Prognosis remained dismal, to the dismay of many physicians. It is of note, however, that the basic science underlying this disorder was slowly advancing.

\section{Medieval Period}

The next great historical contribution for treatment of SCI is credited to Paulus of Aegina (625-690). ${ }^{2,6,11,14} \mathrm{He}$ promoted and modified the Hippocratic method of traction for spinal dislocations and was reported to use the "hot iron." More importantly, he is the first to hypothesize the concept of decompressive surgery/laminectomy for the treatment of this disorder. Additionally, he is credited as the first advocate for surgical removal of fractured spinous processes to relieve pain. ${ }^{11,14}$ For the first time, surgical therapy is introduced as a possible treatment for this disorder. This concept, however, was not universally accepted. LanFrank (1300), who is credited with the first descriptions of peripheral nerve suture techniques, believed that the prognosis in patients with dislocations of the spine was "hopeless.",214 Guy de Chauliac (1300-1368), considered by many to be the father of modern surgery, had similar sentiments regarding prognosis in patients with SCI. He wrote, "One should not labor to cure the paralysis of spinal cord injury,"6,14 an attitude very similar to those of his colleagues preceding him by 3000 years. Physicians in Eastern and Middle Eastern cultures such as Albucasis (12th century) (Figs. 6 and 7) had similar experiences with patients suffering from SCI. ${ }^{11}$ Treatments advocated in these regions are similar to the traction-related therapies in the Western cultures.

\section{Renaissance Period}

This period of history, which is known for the flourishing of knowledge, arts, and sciences, unfortunately did not herald the development of significant changes in the ap- 


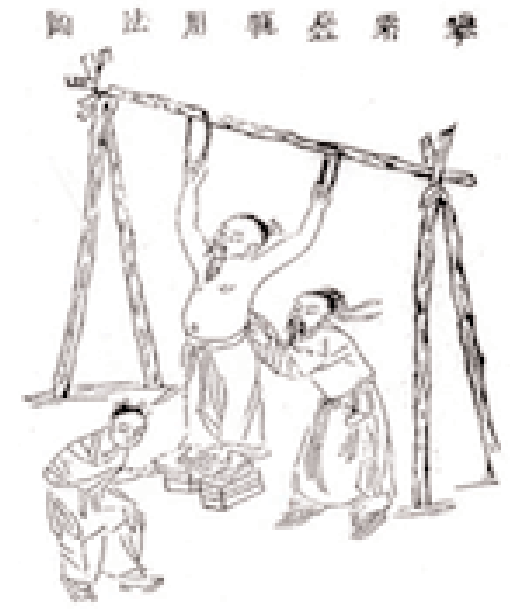

Fig. 6. Abulcasis (963-1013 AD). Chirugia III MS folio 76v, Vienna National Library. Reprinted with permission.

proach to SCI. This period is characterized by the use of variations of prior therapeutic modalities described centuries before. Petrus de l'Argelata (1531) ${ }^{11,14}$ described his method of reducing cervical fracture dislocations by applying force to the greatest point of angulation. Ambroise Paré, the famous French army surgeon, in his Dix-Livres de Chirurgie (1564), ${ }^{6,11,14}$ described his variation of the Hippocratic extension methods to reduce similar fracture/dislocations. He is noted, however, for his aggressive approach in certain injuries to the spinal column; he resected depressed bone fragments impinging on the cord and nerve roots. Fabricius Hildanus (1646) ${ }^{14}$ was the first to introduce a procedure that we still perform today: the open reduction of cervical fracture/dislocations following the failure of closed reduction. He inserted a clamp through the nuchae and spinous processes of the neck and applied traction; if this failed to reduce the deformity he advocated open decompressive surgery and internal re-

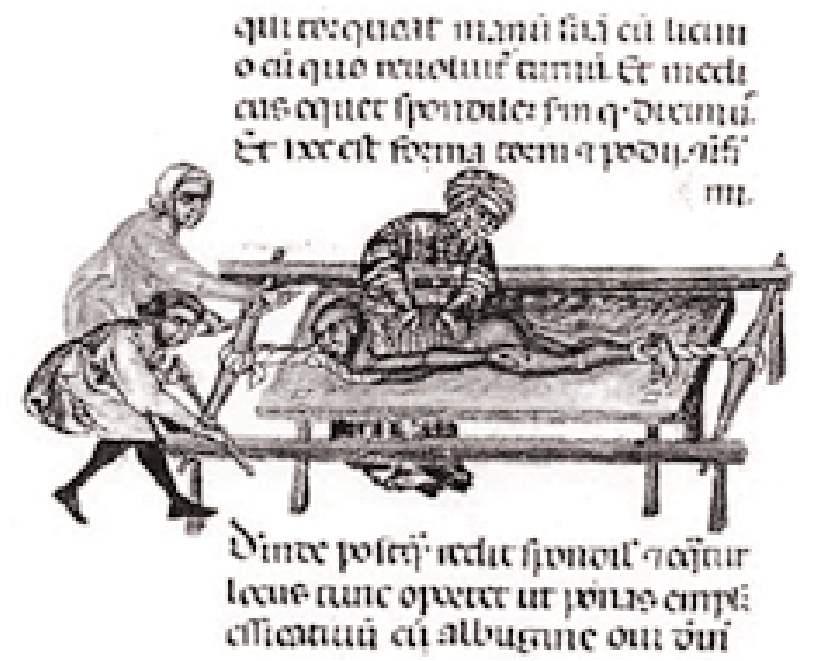

Fig. 7. Treatment of the spinal column. From: Golden Mirror of Medicine: 1959, (94:8). duction of the dislocation (Fig. 8). ${ }^{14}$ Attitudes regarding prognosis remained bleak. A noted feature in this period is the lack of further basic science understanding of the disease process. Therapy remained on treatments aimed at the damaged osseous elements.

\section{Pre-Listerian and Listerian Periods}

In the next 200 years there was increased debate surrounding surgical therapy for SCI as well as anecdotal reports of outcomes after these invasive techniques. The 18th century was characterized by favorable impressions toward surgery. James (1745) advocated operative intervention for spinal dislocation. ${ }^{14}$ Heister (1768) passionately promoted surgery for the treatment of vertebral injuries and SCI. These beliefs were based more on emotional sentiments than firm scientific foundations. ${ }^{14}$ Geraud (1753) reported the removal of a bullet from the L-3 region, with improved neurological outcome. In a similar fashion, Louis (1762) reported a similar case in which decompression of bullet fragments in the lumbar spine resulted in complete functional recovery of lower-extremity movement. It must be noted that these descriptions illustrate the lack of distinctions made between the cauda equina and spinal cord. Enthusiasm for surgical intervention increased even more during this period as evidenced by the writings of Desault in 1796, in which he advocated the decompression of the spine for SCI, even in the absence of vertebral fractures. ${ }^{14}$

During the 19th century, debate raged about the efficacy of surgery for SCI, which tempered the initial enthusiasm of the prior century. ${ }^{10}$ Henry Cline (1814) performed a decompressive laminectomy in a patient who suffered a thoracic fracture dislocation and complete paralysis. This patient did not experience clinical improvement and subsequently died 9 days postoperatively. ${ }^{6,11,14}$ Tyrell, in 1827, reported dismal results after surgical intervention in patients with SCI. ${ }^{14}$ The results reported by Rogers in 1835 were equally discouraging. ${ }^{14}$ Wright of Baltimore (1828) provides very detailed and dismal clinical descriptions of 
patients with SCI during this period. ${ }^{3}$ Because of these poor outcomes, the general tendency in the treatment of SCI, through the remaining decades of the 19th century, was generally conservative, ${ }^{6,14}$ with leading physicians arguing against the use of surgery. The general consensus was best be summarized by the famous English neurologist Dr. Charles Bell in 1824: "Laying a patient upon his belly and by incisions laying bare the bones of the spine, breaking up these bones and exposing the spinal marrow itself, exceeds all belief," 6 and surgery was considered "formidable," "appalling," "bloody, dangerous and unjustifiable."14

Not all experiences with surgery during this period, however, were so negative. English surgeons such as Astley Cooper (1827), Benjamin Bell, and South still favored its application, despite such poor outcomes described by their colleagues. ${ }^{10,14}$ Clearly the debates were fueled both by clinical data and the forceful personalities of these medical giants.

It was in the face of this great debate that Dr. Alban Gilpin Smith of Danville, Kentucky, performed the first successful lumbar laminectomy for trauma injury in the US in 1829. ${ }^{10,11,14}$ Smith received his medical training in Philadelphia with Joseph Parrish. On his return to Danville, he treated a young man with lower-extremity progressive paraparesis suffered after falling from a horse 2 years previously. Smith removed the spinous process and lamina of the affected region, decompressing the neural elements (Fig. 9). ${ }^{10}$ The patient recovered from the procedure and was reported to have an increase in lower-extremity sensation. ${ }^{10,11,14}$ Smith reported this case in the North American Medical and Surgical Journal and in the process introduced the possibility of positive surgery-related outcomes. Smith later moved to the Medical College of Ohio in Cincinnati, subsequently moved to New York, changed his name to Goldsmith, and became chairman of surgery at the College of Physicians and Surgeons, where he focused on genitourinary procedures. ${ }^{10}$

Other prominent developments during this period included Bell's 1824 descriptions of the types of neurological derangements that resulted from trauma: the distinction between flaccid and spastic paralysis; the concept of spi-

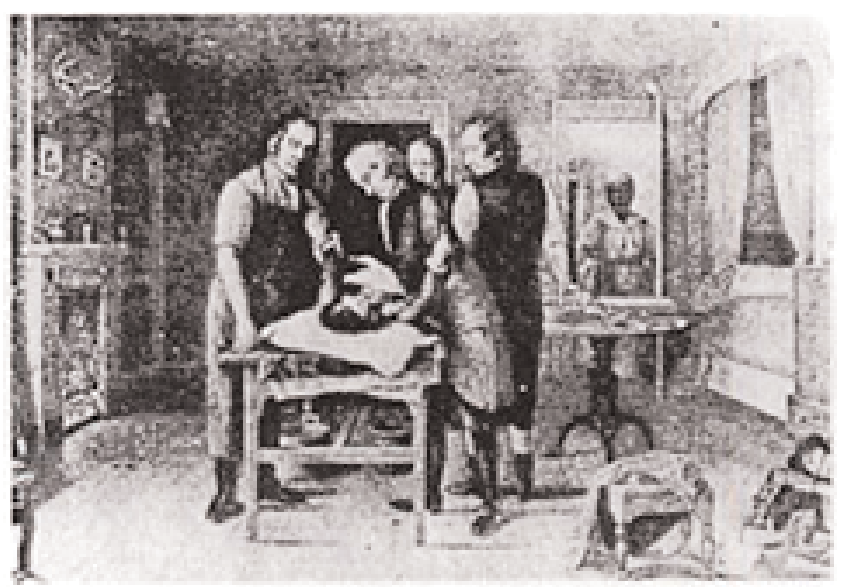

Fig. 9. Alban Gilpin Smith (second individual from the right). Reproduced with permission of Lippincott-Raven Publishers. nal shock; and the dysfunction associated with the bladder and bowel. ${ }^{11,14}$ In addition, attempts were made, as late as 1905, to reestablish direct connections between the injured spinal cord and spinal roots. Success varied but it is believed the positive responses were spinal reflexes rather than signs of regeneration. ${ }^{14}$

The middle and latter part of the 19th century was exciting with regard to development and progress in diverse medical disciplines. The foundations of neurology, neuroanatomy, and anatomical diagnosis and localization were being established. ${ }^{10}$ Modern surgical therapy also originated in this period. The work of Pasteur, in bacteriology, culminated in the development of aseptic surgery by Lister in 1867. ${ }^{10,11,14}$ Infection, which was a great limitation to successful surgery, as well as the overwhelming cause of perioperative death, was conquered. ${ }^{11}$ Almost simultaneously, Wells described in 1844 the narcotic effect of laughing gas. ${ }^{11}$ This work was followed by the first clinical applications of effective, humane anesthesia; in 1848 William Morton, at the Massachusetts General Hospital, used ether to induce a state of anesthesia. ${ }^{10,11}$ It certainly was not "humbug." This development allowed for careful, deliberate surgery without the pain and agony suffered by both patient and surgeon. ${ }^{10}$

It is clear that the physicians of this period, similar to those today, attempted to treat patients with the best available methods. Although their passion was clearly evident and efforts admirable, the scientific foundations of this disorder and of neuroanatomy in general were not fully delineated. Consistent therapeutic success could not be achieved in this environment. Further advances in basic science would be required before progress could be made. Specifically, clinical progress would only follow from a better understanding of the pathophysiology of this disorder, and such insight could only be obtained through experimentation with reproducible and consistent models. It is in this direction that science and medicine proceeded at the end of the 19th and beginning of the 20th century.

\section{Twentieth Century Experimental Developments}

Early attempts to produce experimental spinal trauma were, at best, unsophisticated by modern standards. In reports of work (1890) in rabbits, Schmaus noted degeneration and cavitation in the traumatized spinal cord. ${ }^{4}$ This work was confirmed by Bikeles in 1900. Lugenberger, who studied lesions in guinea pigs, reported the degeneration of the anterolateral white matter tracts after traumatic injury. ${ }^{4}$ McVeigh in 1907 pressed on the exposed cords of dogs to create hemorrhage and edema in the cord. ${ }^{4}$ Thompson used the end of a scalpel to perform similar experiments and obtain similar results. ${ }^{4}$ Other investigators used various models and applied different trauma-related methods to the spinal cords. The problem investigators faced at this junction was that these experimental lesions were not standardized or quantifiable. Hence, therapeutic options could not be tested in any reproducible manner.

In 1911 the neurologist Alfred Reginald Allen made his lasting and influential mark in the study and treatment of SCI. ${ }^{4,16}$ Allen was born in Pennsylvania, the descendant of English Quakers. He inherited a rich capacity for music and mathematics, and possessed a great intellectual curiosity that would inspire him throughout his career. ${ }^{16} \mathrm{He}$ at- 
tended Lehigh University, and matriculated at the University of Pennsylvania Medical School, graduating in 1903. He remained at the university, joining its department of neurology. His major achievements were in the study of spinal trauma, between 1908 and 1914. ${ }^{16}$ Allen developed a research model for experimental SCI, using graded weights. This model was reproducible, quantifiable, and induced standardized lesions (Fig. 10). ${ }^{16}$ For the first time, it was possible to accurately vary the force applied to the spinal cord and correlate that with clinical and pathological findings in the cord. Allen's weight drop technique, with some modifications (Tarlov, Gelfan, and Amako) remains the basis by which experimental lesions are created today. ${ }^{4,16}$ During this period, Allen, through his observations, was able to postulate that toxins may create secondary damage to an injured cord. This is a very early description of what we term secondary injury. Allen also promoted the concept of early decompressive surgery in a traumatic cord region to allow necrotic debris and blood products to extravasate from the injured region.,16 His career, unfortunately, was abruptly interrupted by the outbreak of World War I. He, like many of his generation, joined the US Army and was able to attain the rank of major. Curiously, Allen joined the combat forces rather than the medical corps, like most of his colleagues. He was killed in the battle of the Argonne Forest in 1918. To this day, he is the only member of the American Neurological Association killed in military service in the history of the organization. ${ }^{16}$ His influence in this endeavor of study resonates to this day.

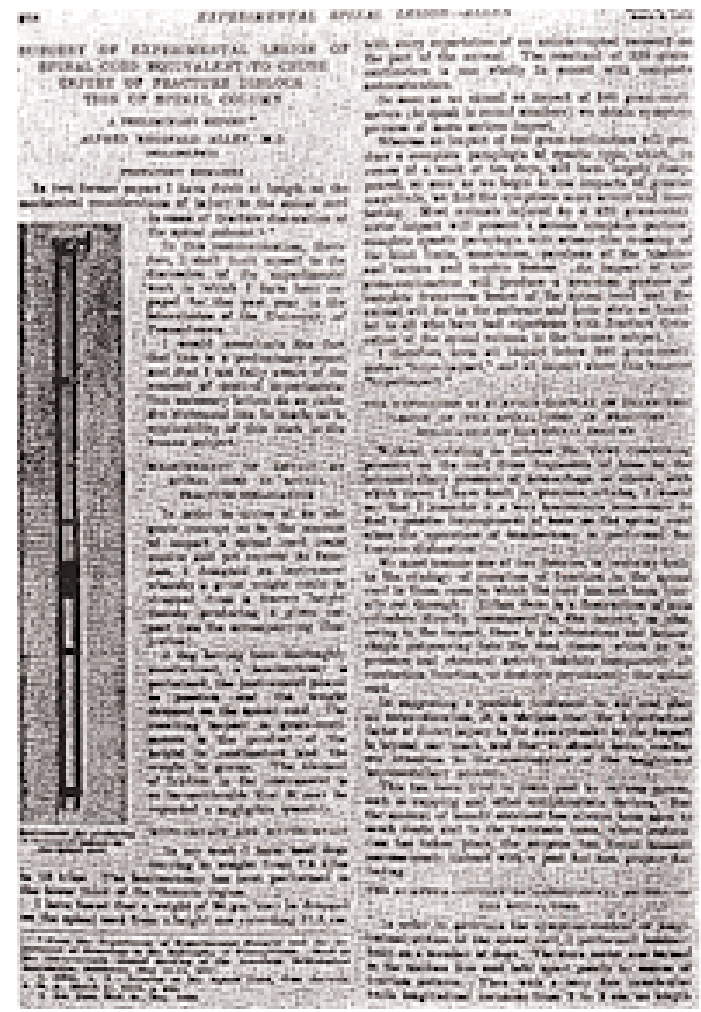

Fig. 10. Instument designed by Dr. Allen for graded impact upon the spinal cord.
During the next several decades there were great advances in the technology used in basic science research. These technological advances were applied to the study of SCI, however slowly. In their studies of acute and chronic compression of the spinal cord, Tarlov and Gelfan concluded that reversible conduction block obtained by experimental compression was secondary to mechanical pressure, not hypoxia. ${ }^{4,9}$ The technique of circumferential extradural compression of the spinal cord was developed by Tator who described demyelination of the lateral white matter tracks and cavitation of the gray matter within the first few months after the trauma. ${ }^{4}$ Albin and White of Cleveland (original collaboration at Mayo Clinic) applied local hypothermia treatment to the regions of trauma within 4 hours of injury in animals that consequently regained sensory and motor function. More delayed application did not result in any clinical benefit. Of note, they were eventually able to apply the technique clinically in several patients; however, success was not achieved (the interval between injury and treatment was $>4$ hours, however). ${ }^{4,18}$ In 1969, Ducker proposed the use of steroid agents in SCI within 3 hours of insult. ${ }^{4}$ In the same year Hartzog published his experiences of administering hyperbaric oxygen in SCI. ${ }^{4}$ In 1969, Tomasula published his positive results of posterior myelotomy after experimental SCI. ${ }^{4}$

In the 1970s Osterholm and Mathews demonstrated an increase in norepinephine levels in the gray matter after SCI. They introduced the concept of pharacoltherapy for patients with SCI; ${ }^{4,17}$ intervention in blocking norepinephine synthesis by administering $\alpha$-methyltyrosine 15 minutes postinjury, with encouraging results. ${ }^{4}$ In the $1980 \mathrm{~s}$ investigators studied the role of endorphins, thyrotropinreleasing hormone, calcium channel blockers, opiod antagonists, dexamethasone, 21-aminosteroids, epsilon carporic acid, and hyperbaric oxygen; the results of each of the studies were encouraging. ${ }^{17}$

In 1990, Bracken, Collins, and members of their national spinal cord research study reported the clinical outcomes obtained in patients who received supraphysiological doses of methylprednisolone in the treatment of nonpenetrating adult SCI. They found that in patients who received this treatment within 8 hours of injury, a slight but statistically significant improvement in their functional status was demonstrated. ${ }^{17}$ While this study and their subsequent North American Spinal Cord Injury Study III in 1997 received substantial criticism and much controversy surrounds its application, its place in the history of SCI is significant. It was the first time, in the history of humans, that a therapy was shown to produce reproducible neurological improvements in human SCI. (Lloyd Guth, SCI techniques course at UCI Reeve-Irvine Research Center, Fall 2000; unpublished data).

\section{Twentieth Century Clinical Developments}

Similar to the basic science advances in SCI witnessed during this century, advances in clinical approaches were also extraordinary. In this century surgery became both safer and more routine. Surgical approaches were developed to allow the safe approach to any region or level of the spine, from any side whether the desired objective is the anterior, posterior, or the lateral portions of the vertebrae. At the same time insight into biomechanics in- 
creased, spine surgery benefited from the wide application of instrumentation (particularly once Harrington rods were introduced in the $1960 \mathrm{~s})^{11}$ and other techniques (bone morphogenetic protein and platelet mix) to promote fusion and stabilization of abnormal or traumatized motion segments. In the late 1960s and early 1970s the intraoperative microscope was introduced, with its improved lighting and better visualization of surgical structures. Furthermore, anesthetic technique improved and become safer as the century progressed.

During this century, the medical field witnessed the development of life-saving prehospital care, and rapid prehospital transport, with proper stabilization of unstable spinal segments. This led to decreased morbidity and mortality rates in this population. The relatively recent developments and techniques of critical care medicine have been applied in patients with SCI, to address the various medical issues that challenge patient care in the acute setting. Our neurodiagnostic capabilities significantly evolved, from use of plain radiography and plain tomography to CT scanning in the $1970 \mathrm{~s}^{15}$ and to MR imaging in $1976,{ }^{15}$ with its unparalleled ability to visualize the spinal cord and its injured segments directly.

Perhaps some of the greatest clinical advances in the care of patients with SCI during this century have been in physical therapy and rehabilitation. In World War I 80\% of individuals with SCI died in the first 2 weeks. ${ }^{6}$ Dr. Cushing, in his role as consultant neurosurgeon to the American army commented: "The conditions were such owing to pressure of work, as to make it almost impossible to give these unfortunate men the care their conditions require. No water beds were available, and each case demands undivided attention of a nurse trained in the care of paraplegics. ..." 6

Problems associated with patients with SCI included infection of the kidneys/bladder, kidney failure, pressure sores, and depression. ${ }^{1,5,6}$ Physicians at the end of World War II championed various allied governments for the development of specialized units, dedicated to the treatment and rehabilitation of these patients, to manage their needs in a comprehensive manner. ${ }^{5}$ Two primary leaders in the development of these units were Sir Ludwig Guttmann of the UK, and Dr. Donald Munro of Boston..$^{1,5,6}$ Through their efforts, and the efforts of their pupils, the complication and mortality rates in this population significantly decreased. Today, centers such as these are found in just about every part of the world, and patients are gradually integrated back into society.

\section{Twenty-First Century and Beyond}

The most recent advances in experimental SCI investigations exist in the disciplines of neurobiology.7,9 The discovery of stem cells and their application in SCI appears to be promising. ${ }^{79,17}$ The inhibitory role of central nervous system myelin in the regeneration of axons is being elucidated; this discovery has led to the development and study of various antibodies against these targets to promote spinal cord recovery. ${ }^{917}$ In addition, our knowledge of trophic factors and the inflammatory process after SCI is evolving at an extraordinary rate. These areas are fertile topics currently being explored. Clinically, functional neuromuscular stimulation may provide the patient with SCI direct control over various portions of the body through computer and electrical impulses. ${ }^{7}$ Developments in this area are rapid and offer exciting opportunities for the future. Further advances in MR imaging technology may allow both researchers and clinicians to visualize SCI on a molecular level with the progress in MR spectroscopy. ${ }^{15}$ The information provided by this new technology may play a very practical role in future clinical decision making. Perhaps, however, the most important focus for clinicians in the future will be in the prevention of SCI, ${ }^{7}$ which will require the physician to assume the role of educator to the general public, including school children, teenagers, and legislators. As a community, we will find a balance between awareness and caution so the general public is educated but not made fearful. ${ }^{7}$ Clearly, on all fronts, the future in the field of SCI management is exciting.

\section{CONCLUSIONS}

Great advances and achievements have been made over the course of medical history. In this new millennium clinicians will be required to face the challenges presented by SCI. With current research in molecular biology, gene therapy, and neural regeneration, the outlook for this process can be shifted from " an ailment not to be treated," to one that can be both treated and potentially cured. As in the past, the integration of the discoveries in basic science and clinical innovation will continue to lead the path. We truly are now standing on the shoulders of giants, with the goal to "make man whole" (Loma Linda University Medical Center slogan).

\section{Acknowledgment}

Dr. Lifshutz thanks Dr. Dennis Maiman for his help, support, and assistance with this project as well as throughout his fellowship.

\section{References}

1. Bedbrook GM: The development and care of spinal cord paralysis (1918 to 1986). Paraplegia 25:172-184, 1987

2. Browne KM: Surgery of the peripheral nerves, in Walker AE (ed): A History of Neurological Surgery. New York: Hafner, 1967, pp 396-424

3. Carroll DG: History of treatment of spinal cord injuries. Md State Med J 19:109-112, 1970

4. Dohrmann GJ: Experimental spinal cord trauma. A historical review. Arch Neurol 27:468-473, 1972

5. Guttmann L: New hope for spinal cord sufferers. Paraplegia 17:6-15, 1979

6. Guttmann L: Spinal Cord Injuries: Comprehensive Management and Research, ed 2. Oxford, UK: Blackwell Scientific, 1976, pp 1-176

7. Harris P: Spinal cord injuries in the 21st century. J Am Paraplegia Soc 14:55-57, 1991

8. Hughes JT: The Edwin Smith Surgical Papyrus: an analysis of the first case reports of spinal cord injuries. Paraplegia 26: 71-82, 1988

9. Kakulas BA: The applied neuropathology of human spinal cord injury. Spinal Cord 37:79-88, 1999

10. Keller T, Holland MC: Some notable American spine surgeons of the 19th century. Spine 22:1413-1417, 1997

11. Knoeller SM, Seifried C: Historical perspective: history of spinal surgery. Spine 25:2838-2843, 2000

12. Marketos SG, Skiadas P: Hippocrates. The father of spine surgery. Spine 24:1381-1387, 1999 


\section{J. Lifshutz and A. Colohan}

13. Marketos SG, Skiadas PK: Galen: a pioneer of spine research. Spine 24:2358-2362, 1999

14. Markham JW: Surgery of the spinal cord and vertebral column, in Walker AE (ed): A History of Neurological Surgery. New York: Hafner, 1967, pp 364-392

15. Perovitch M, Wang H, Perl S: The evolution of neuroimaging of spinal cord injury patients over the last decade. Paraplegia 30:39-42, 1992

16. Schlesinger EB: Alfred Reginald Allen: the mythic career of a gifted neuroscientist. Surg Neurol 36:229-233, 1991

17. Theodore N, Sonntag VKH: Spinal surgery from the Eisenhower years to the third millennium, in Barrow DL, Kondziolka D, Laws ER, et al (eds): Fifty Years of Neurosurgery. Philadelphia: Lippincott Williams \& Wilkins, pp 281-294
18. White RJ: Historical development of spinal cord cooling. Surg Neurol 25:295-298, 1986

Manuscript received November 17, 2003.

Accepted in final form December 12, 2003.

Address reprint requests to: Jason Lifshutz, M.D., 1110 East Ogden Avenue, Apartment 303, Milwaukee, Wisconsin 53202. email: jlifshutz@neuroscience.mcw.edu. 